Teaching \& Learning (2013/2014) 8(1), 20-34

\title{
Beyond Understanding: An Exploration of Teacher Knowledge through a Wholistic Lens
}

\author{
NINA LEE WEBSTER \\ Brock University
}

\begin{abstract}
Teacher knowledge goes beyond understanding children's cognitive and social development, comprehending pedagogy, and teaching the curriculum. It involves many facets and layers of a teacher's personal identity, epistemological interests, experiences, perceptions, and beliefs, regarding the purpose and meaning of teaching and learning. The four categories of Shulman and Shulman's (2004) model of teacher individual knowledge are used as a conceptual framework. Through a wholistic approach, the inseparability and interconnections of the underlying constructs and understanding is highlighted. Teacher knowledge is viewed as both the conscious and unconscious aspects that impact or influence teaching. Through this lens, the person is equally as important as their competencies. Drawing on the work of Dr. Ellen Langer and Buddhist Thich Nhat Hanh, mindfulness is explored as a significant component necessary in intrinsic teacher development. This missing component may aid teachers in becoming stronger educational thinkers, questioners, and ultimately, knowers.
\end{abstract}

\section{Introduction}

In 1986, Shulman inquired: What are the sources of teacher knowledge? What does a teacher know and when does he/she come to know it? While these critical questions were inquired decades ago, they are highly pertinent to our current (and ever changing) conception of teacher knowledge. With growing globalization, stress on knowledge economies and technology, and emphasis on classroom differentiation, teachers must obtain qualitatively different types of knowledge (Eilam \& Poyas, 2009; Freeman, 2002; Martinez, 2010; Shulman, 1986; Valentine \& Ivey, 2008). The pinnacle of my interest in teacher development lies in an exploration of teacher knowledge from an all-encompassing - interdisciplinary - wholistic lens. Within this article, the spelling of wholistic with a "w" is intentional. The root word whole emphasizes the act of constituting the complex unity, total sum, of parts, fitting together as one (Whole, n.d.). In contrast, the word hole emphasizes a missing gap or weakness, a dreary place, or a perforation (Hole, n.d.). 
Teacher knowledge goes beyond understanding children's cognitive and social development, comprehending pedagogy, and teaching the curriculum. It involves many facets and layers of teacher's personal identity, epistemological interests, experiences, perceptions, and beliefs, regarding the purpose and meaning of teaching and learning. Much research has been dedicated to investigating the knowledgebase of teaching in hopes of formulating highly structured, yet effective teacher education programs and curricula (Verloop, Driel, \& Maijer, 2001). To this end, our understanding of qualities of 'successful' or 'exemplary' teachers has been fragmented, and teacher education has become highly mechanistic (Ahmadian \& Tavakoli, 2011; Briggs \& Peat, 1989; Cvetek, 2008; Davis, Sumara, \& Luce-Kapler, 2008). In several instances, teacher education has directed its focus primarily onto the development of these fragmented qualities. Yet, it is imperative to develop and understand these qualities within a broader perspective, to appreciate and support their influential and interconnectedness within the teacher as a whole. Without an understanding of the self as a system, these qualities may never reach their full potential and impact (Davis, Sumara, \& Luce-Kapler, 2008; Shulman \& Shulman, 2004). Additionally, the research produced has limited generalizable findings, since teacher knowledge as a whole is complex, interdependent, interpreted, cultured, personal, and situated (Beattie, Dobson, Thornton, \& Hegge, 2007; Freeman, 2002; Martinez, 2010; Musanti \& Pence, 2010; Putnam \& Borko, 2000; Shulman \& Shulman, 2004; Verloop, Driel, \& Maijer, 2001). For many years, lack of understanding how the human mind functions and complexity of teaching, has been disregarded in hopes of discovering an efficient and fail-proof method of systematic teacher development. It is only recently that the complexity of knowledge and unpredictability of teaching have made an appearance in the forefront of studies on teacher knowledge.

Still, teacher development, as well as the love of learning evidenced in teachers, is certainly not developed solely in teacher education - through a personal transformation the foundation is laid before then (Korthagen, 2004; Musanti \& Pence, 2010; Shulman, 1987; Shulman \& Shulman, 2004). Yet, many studies have focused on teacher education as being the onset of teacher knowledge, as well as development (Chai, Koh, \& Tsai, 2010; Korthagen, 2004; Shulman, 1987). Many scholars actually equate teacher development and related knowledge with teacher education. In these studies, research is focused on observable and measurable teacher behaviours, beginning at the pre-service level. It is only recently that teachers' cognition, the 
underlying influences of teaching behaviours, is being explored (Freeman, 2002; Verloop, Driel, \& Maijer, 2001). Further influences on teaching behaviour may include research and knowledge cultures, social systems, beliefs and ideologies, and even popular culture (Kiraz \& Ozdemir, 2006; Musanti \& Pence, 2010). The influences on teaching behaviour are ever-changing and highly individualistic. In response to the multidimensionality, the wholistic approach provides an integrative framework to examine the modern conceptions of teacher knowledge. With such a

dynamic, elusive, and individualized concept, many theoretical lenses have already engaged, interpreted, and reported on this phenomenon. Rather than contradicting the various perspectives, all findings should be appreciated and presented through a universal view (a wholistic lens). The rationale of this research is to initiate a larger conversation regarding the necessity of fostering teachers' wholistic perception of reality. In the teaching profession, a mindful mindset is necessary for survival in the context of an active and chaotic environment. It is also necessary for teachers to obtain a clear perception of reality, in its totality, by understanding the constituent elements within the interconnected whole. This paper aims to grapple with the concept of teacher knowledge, in hopes of illuminating some of the underlying dimensions of teacher development, contributors to knowledge acquisition, and to identify areas for future research.

\section{The Nature of Cognition and Learning: Situatedness}

A collective theme presented in the literature is the situatedness of cognition (knowledge, thinking, and learning). Cognition is situated in physical and cultural contexts, as well as social in nature, and distributed between individuals, groups, and tools (Brown, Collins, \& Duguid, 1989; Freeman, 2002; Martinez, 2010; Musanti \& Pence, 2010; Putnam \& Borko, 2000). Consequently, the situatedness becomes a fundamental part of what is learned, or the knowledge gained.

Interestingly, most of these considerations and related educational implications are discussed in the literature, in relation to students (Putnam \& Borko, 2000). Nonetheless, the concept of situated cognition has many important implications for an understanding of teacher knowledge, its acquisition, and its development. In terms of 'what teachers know and how they know it', the literature states that meaningful learning only occurs when it is embedded in authentic activity (Brown, Collins, \& Duguid, 1989). Knowing this, it becomes apparent that teacher knowledge requires purposeful learning opportunities through authentic activities, as 
well as personal relevance and meaning to the individual. Within Shulman and Shulman's (2004) model of individual analysis, situatedness would have a considerable impact on all aspects of our individual reflection, and overall teacher knowledge.

\section{Teacher Knowledge}

Teacher knowledge incorporates more than intellectual abilities, pedagogies, and academic content (Musanti \& Pence, 2010; Shulman, 1986; Valentine \& Ivey, 2008). Shulman and Shulman (2004) identified four categories of teacher individual knowledge, including: readiness (vision), ability (understanding), willingness (motivation), and reflective practice (see Figure 1). These categories are presented throughout the literature in the area of teacher knowledge, under similar or related headings. Moreover, Shulman and Shulman (2004) state that teachers may have strengths in some, all, or none of these categories. These categories will serve as a frame for the review of literature on teacher knowledge.

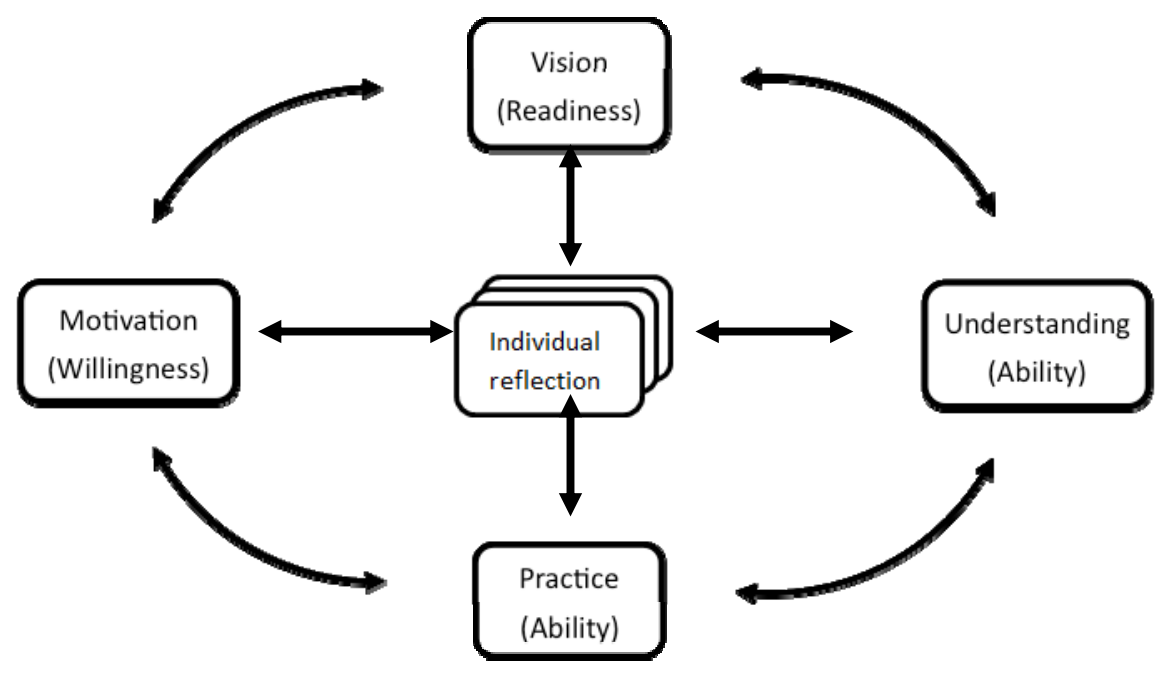

Figure 1. Shulman \& Shulman's (2004) model of individual analysis

Understanding and practice. Upon initial consideration of teacher knowledge, the notion of ability and understanding came to mind. The ability category includes the understanding of curriculum content, learners, and pedagogy, as well as the capability to engage, to manage, to implement, to organize, and to assess (Shulman, 1987; Shulman \& Shulman, 2004). This category has been the predominant focus of teacher knowledge and development 
research (Beattie, Dobson, Thornton, \& Hegge, 2007). Although this category encapsulates teaching-related understanding, De Vries (2003) adds depth to the category as she states that "understanding is more than information take-in; learners structure, organize, and generalize raw information... Understanding is never finished...” (p. 162). It is evident that the deeper cognitive processes associated with understanding, are also necessary to consider within this category.

Vision. Readiness is described by Shulman and Shulman (2004) as having a developed educational vision that is active, constructive, and metacognitive. Readiness also includes a repertoire of activities, understanding of teaching and learning as a cyclical process, and ability to articulate one’s vision (Martinez, 2010; Shulman \& Shulman, 2004). The vision, in a sense, is a goal in which teachers strive towards, as well as their individual standard of teaching. To guide and enhance readiness for teaching, teachers must become aware of the rich, broad, and deep significance of their work (Beattie, Dobson, Thornton, \& Hegge, 2007). Through this critical self-awareness, teachers' visions and horizons meaningfully transform, expand, and extend.

Motivation. Willingness, motivation, and volition are required to pursue and act on goals (Korthagen, 2004; Martinez, 2010). Shulman and Shulman (2004) ask what kind of cognitive disequilibria are useful in fostering such motivational development, as well as to what extent 'willingness' is an internal category. While there may be levels or stages of sustained motivation, commitment, or meaningful involvement, these are likely to result from positive emotional associations linked to personal reward (Martinez, 2010). This is echoed by Kiraz and Ozdemir (2006), who state that inharmonious clashes, between cognition and behaviour, will lead to change, in hopes of re-establishing harmony. Since beliefs and educational ideologies are ingrained from years of formation, it is often the behaviour that undergoes the change (Beattie, Dobson, Thornton, \& Hegge, 2007; Kiraz \& Ozdemir, 2006; Korthagen, 2004; Wubbels, 1992).

Individual reflection. All teachers must be knowledgeable in reflective practice with the aim of purposefully adapting and learning from experiences. Critical analysis of teaching practice and student learning are at the heart of education (Shulman, 1987; Shulman \& Shulman, 2004). Through metacognitive reflection, teachers become more conscious of their ideas, thoughts, knowledge, performance, and dispositions (Martinez, 2010; Shulman \& Shulman, 
2004). Through praxis of structured reflections, rooted in both vision and ideological beliefs, their thoughts and experiences may evolve towards better, stronger, and more effective ideas (Martinez, 2010; Shulman \& Shulman, 2004).

Teacher knowledge is multifaceted and requires favourable environments that can support, sustain, and fine-tune diverse visions, abilities, motivations, and reflections. While the thought of teacher knowledge often elicits intellectual abilities, pedagogies, behavioural aspects, and academic content, it is necessary to consider the often unconscious emotional, volitional, and personal factors that hinder or enhance teacher knowledge (Korthagen, 2004; Martinez, 2010). It should be an aim of all teachers to become wholly competent in teacher knowledge.

\section{Conceptual Analysis: A Wholistic Approach to Frame Teacher Knowledge}

The wholistic approach aims to fully engage all aspects of a person in development. In education, the degree to which this approach is used varies, depending on many philosophical, ideological, political, theoretical, practical, and situational factors. There is however a tendency for the whole-person approach to be demonstrated in primary classrooms; it is less apparent in higher education, which is often considered to be intellect-dominated, or knowledge-centred. Despite this tendency, there are great benefits that come throughout development, across the lifespan, with adopting this approach.

Wholistic approaches aim to highlight the inseparability found within the interconnections of constructs and underlying understanding (see Figure 2). Hamachek (1999) reiterates this message by saying, “Consciously, we teach what we know; unconsciously, we teach who we are” (p. 209). Rather than exploring the conscious and unconscious as distinctly separate components of teaching, holism attempts to explore this concept by the sum of its parts. Therefore, from the wholistic stance, it is pedagogically undesirable to establish a systematic method of teacher development that is focused on separate components of good teaching (Hamachek, 1990; Korthagen, 2004). Teacher knowledge is a composite entity that cannot be fragmented and narrowly transferred. In reality, there is no single method to this goal, since there are many paths to learning.

Teacher knowledge encompasses the development and harmonious balance of emotional, intellectual, social, physical, creative, and spiritual potentials. With the wholistic approach, it is 
necessary for intrinsic devotion and a passionate love of teaching and learning, to thread through all dimensions of teacher knowledge. Furthermore, considering the praxis nature of knowledge development, it does not make sense to teach expert-methods to beginners in teacher education (Combs, Blume, Newman, \& Wass, 1974). Greater emphasis should be placed on the process, rather than the product of teaching.

Overall, there is a lack of wholistic and humanistic approaches in teacher education that frame teacher knowledge and development. More attention is required on the teacher as a person, as opposed to a carrier of competencies. While Shulman and Shulman (2004) provide an excellent springboard for the exploration of the seen and unseen aspects of teacher knowledge, the wholistic approach may further probe into its foundations. Shulman \& Shulman’s (2004) model highlights traditional views of teaching, as demonstrated in the static view of teacher ability. Complex systems argue that teaching and learning situations are not so linear; rather, they are complex with several external and internal constituents (Cvetek, 2008).

\section{Discussion: Architecture of Self as Teacher}

Martinez (2010), Shulman (1986), and Flavell (2004) have stressed the multi-layered nature of knowledge, knowledge acquisition, and knowing. Areas of knowledge are hotly debated and widely studied in the field of education. In response to the breadth of knowledge paradigms, teacher knowledge requires a conception of the interplay and transformation of teachers’ worldview, situatedness, intellectuality, schooling, cultural upbringing, and perceptive factors of learning (Flavell, 2004; Gaudelli \& Ousley, 2009; Langer, 2000; Martinez, 2010). Our own lifepaths evidently shape who we are as teachers, what we know, and how we know it. While life and personal influences seem obvious to some, they are less obvious (or less welcomed) by others. These aspects of self are considered to be a major component to the development of teacher knowledge. As such, they were added as an extension to Shulman and Shulman's (2004) model as Personal Cognitive Constructs (see Figure 2).

Today, more attention is given to the perspectives, beliefs, and attitudes that people have about themselves as people, and more specifically, as professionals. This professional identity asks the questions: who am I? and What kind of teacher do I want to be? (Beattie, Dobson, Thornton, \& Hegge, 2007; Korthagen, 2004). The answers to these questions are not always clear-cut, and are highly individualistic, since our self-image is greatly dependent on our 
personal histories (Korthagen, 2004). Thus, through the wholistic lens, the more that teachers know about themselves, their personal hidden curriculum, the stronger their teacher knowledge and growth potential may be (Freeman, 2002; Hamachek, 1999). Through becoming in sync with their complex ways of knowing and development, teachers may answer the questions of professional identity on a deep, yet conscious level. Nonetheless, it is found in the literature that many teachers are not interested in self-understanding, or in unveiling the Gestalt of their professional identity - identifying their unconscious needs, feelings, values, roles, models, previous experiences, and tendencies (Beattie, Dobson, Thornton, \& Hegge, 2007; Freeman, 2002; Korthagen, 2004; Verloop, Driel, \& Maijer, 2001). In a fast-paced, individualistic, goaland knowledge-driven society, the resistance to move beyond competency development becomes understandable. With consideration to the Canadian cultural context, the personal and professional value of discomforting cognition, questioning, and deep understanding, is undermined and unappealing (Evans, Arnot-Hopffer, \& Jurich, 2005; Kabat-Zinn, 1990). Yet, Kabat-Zinn (1990) states that this very discomfort often begins the process of learning and individual growth.

While teachers may possess the qualities of empathy, compassion, understanding, love, and flexibility, their lack of interest in self-understanding is fundamentally problematic, since our minds are deeply interconnected to our learning and actions. If teachers are not connected to their unconscious core qualities, they may not stimulate the deep involvement necessary in the teaching praxis (Freeman, 2002; Korthagen, 2004). Through mindfulness mindsets, people become aware and understand their inner mind, and how it influences their choices, perceptions, learning, and actions. The often uncomfortable development of familiarity with one's judgement, prejudices, and mental categorizations, begins the process of learning to recognize them and abolish them (Kabat-Zinn, 1990). Furthermore, the evident disinterest in becoming an accomplished teacher, as opposed to ordinary, is precisely this human connection that is at risk of being lost in the face of systematic knowledge-driven systems (Korthagen, 2004). Teachers must learn the value of active, intentional, and ongoing investigations of one's behaviour, mind, intent, and most importantly, perceptions (Maha Thera, 1990). Across teacher education, there is a general need for a more integrative, mindful, and wholistic approach, to ensure the growth and harmony on various levels of knowledge paradigms (Hyland, 2009; Korthagen, 2004; Langer, 2000). However, this process must be intrinsic, meaningful, and purposeful for the individual. 
The utter significance of this potentially lengthy, discomforting, and conflicting process must be explained, guided, and supported in the face of resistance. Through the habitual practice of personal higher-order thoughts, great benefits can be obtained from daily learning episodes, teaching opportunities, and through “channels of experience” (Martinez, 2010, p. 3).

Mindfulness is a powerful approach that may be used to free individuals from their rigid habits of thinking, learning, and behaving. Through mindfulness, teachers may obtain flexibility in their knowledge development, as they open their minds to new information, identify filters and barriers, and obtain an implicit awareness of the existence of multiple perspectives (Freeman, 2002; Valentine \& Ivey, 2008).

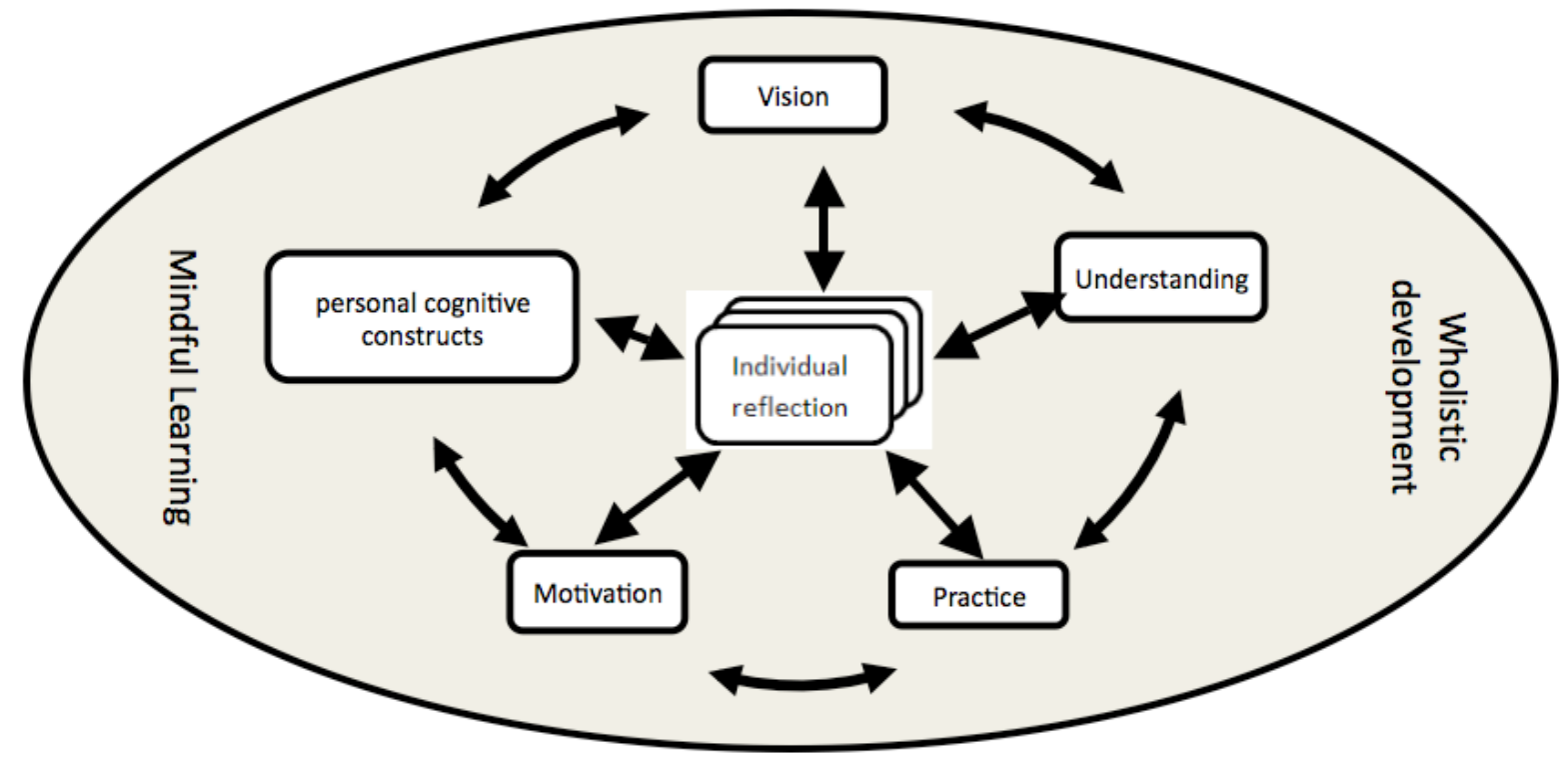

\section{Figure 2: Model of Wholistic development and mindful learning (extension of Shulman \& Shulman's [2004] model)}

\section{Mindfulness}

It is apparent that there is a serious disconnect between teachers' attitudes towards selfunderstanding, and the known benefits (and necessity) of self-understanding for teacher knowledge acquisition and development. Envisioning an effective response to this discussion appears to be unattainable; however, one such response may be the mindful approach or mindfulness learning. 
Drawing on the work of Dr. Ellen Langer and Buddhist Thich Nhat Hanh, cognitive pluralism and ignorance can be minimized with mindfulness. The concept of mindfulness stems from Buddhist teachings and was strongly promoted by Thich Nhat Hanh (1926- ), who emphasizes the nature of inclusiveness, consciousness, genuineness, and deep learning (Hyland, 2009; Langer, 2000; Tremmel, 1993). Mindfulness maintains our personal interconnections and as such, it is both a 'means' and an 'end' in learning (Beattie, Dobson, Thornton, \& Hegge, 2007; Hyland, 2009; Langer, 2000; Valentine \& Ivey, 2008).

Through mindfulness, teachers may learn to become stronger thinkers by questioning their ideas and actions, logic, and connections to prior and current knowledge (Freeman, 2002; Martinez, 2010). Teacher knowledge is a work in progress, requires active effort, and incorporates personal past, present, and future experiences in its development. With this view, teachers may obtain an awareness of the impermanence and uncertainty surrounding both knowledge and development. As teachers inquire into their personal and professional knowledge, they are not looking for superficial answers, but instead they are listening to their inner dialogue invoked by questions (Beattie, Dobson, Thornton, \& Hegge, 2007; Hyland, 2009; Langer, 2000; Valentine \& Ivey, 2008). Mindfulness provides a deep sense of knowing, and a richer personal understanding of self.

With a willingness to engage in mindful thinking, greater willingness for introspection will likely ensue. With an appreciation for the present moment, mindful thinkers understand that they are merely a single individual in a network of complex systems and relationships (Valentine \& Ivey, 2008). With this appreciation, teachers may also take reign of previous unconsciousness, by awakening the mind towards open awareness while performing tasks. Without an understanding and appreciation of the greater whole, reality is reduced to fragments that conceal the interdependence, connections, and networks associated with teacher knowledge (Valentine \& Ivey, 2008). Therefore, through mindful training, learning, and thinking, teachers may obtain deeper levels of professional knowledge, as well as the know-how of accomplished teachers.

\section{Applications}

Teacher knowledge is defined as dynamic, evolving, situated, layered, and constructed (Flavell, 2004; Gaudelli \& Ousley, 2009; Langer, 2000; Martinez, 2010). Furthermore, teachers have their personal knowledge and experiences that also inform and influence their professional 
being. With consideration of the interwoven nature of the personal and professional, as well as the past and present, I share implications for practice, and an agenda for future studies on teacher knowledge.

\section{Implications for Practice}

Teacher education programs may benefit from a wholistic model of teacher knowledge when considering program curriculum, teaching pedagogy, and teacher credentialing. With a wholistic approach, programs may consider focusing on Kabat-Zinn’s (1990) modern interpretations of mindfulness, which includes non-judging, patience, having a beginner's mind, trust, non-striving, acceptance, and letting go. The focus would then shift from rigid, systematic training, to a practice of self-understanding and self-discovery. This would be established through active and intentional explorations of one’s behaviour, mindset, intentions, and perceptions (Maha Thera, 1990). Through this practice, teachers could then become aware of teaching reality in its totality, and understand how their personal cognitive constructs influence their choices, learning, actions, and mind. By addressing the acts that constrain individual growth, teacher education may effectively impact teacher preparedness and teacher knowledge.

\section{Future Directions for Research}

It is recommended that teacher knowledge be explored through additional theoretical frameworks or perspectives. While the outer limits of cognition and wholistic approaches provide a deep examination into the individual, and most particularly the mind, additional research is necessary in the intersections of cognition and sociocultural theories. Through a sociocultural framework, additional perspectives on the influence of discourse communities may be explored.

With the theme of 'teacher as a person' that is embedded throughout this paper, it is recommended that narrative approaches be used in future research. A narrative approach could allow for personal stories, life histories, past influences, including personal upbringing, culture, heritage, beliefs, and schooling. The rich data provided in narratives may illuminate additional humanistic findings with regard to teacher knowledge, teacher development, and professional identities. A well-rounded discussion on teacher knowledge requires a wholistic view of people, with an acknowledgement of the significance and impact of personal history, context, and 
willingness to inquire within the self (Freeman, 2002). It is also necessary to further explore the preconceptions and beliefs of novice teachers. Since beliefs act as a lens and filter the information received and expressed, they warrant greater attention in the study of teacher knowledge (Eilam \& Poyas, 2009; Farrell, 2006; Freeman, 2002; Verloop, Driel, \& Maijer, 2001). It is necessary to explore all potential impediments in knowledge acquisition and growth.

Lastly, there is a growing occurrence of unpredictable scenarios in teaching, due to the changing times (i.e. inclusion, differentiation), pedagogies, and school cultures (Valentine \& Ivey, 2008). We live in a quickly evolving world that makes it, at times, highly uncertain. This uncertainty requires teachers to efficiently adapt, adjust, and transfer their knowledge and skills to many spontaneous scenarios. Much research is required to further understand the processes by which teachers integrate information from various sources into personal and professional frameworks that guide their thinking, feeling, and actions in practice (Verloop, Driel, \& Maijer, 2001).

\section{Conclusion}

While the personal cognitive constructs of teaching and learning has continuously taken the backseat in many studies on teacher knowledge, it is becoming recognized as an important influence on their counterparts, the highly studied explicit teaching behaviours. When examining teachers as an identity with a distinctive knowledgebase, it is necessary to consider the mind, body, and spirit of teaching. This article began with Shulman's (1986) questions: What are the sources of teacher knowledge? What does a teacher know and when does he/she come to know it? Within this paper, the elusive disposition of these questions was exposed in relation to the challenges and resistance to personal analysis in the $21^{\text {st }}$ century.

The environment, culture, and context in which we learn and live are necessary to consider when examining human qualities, interactions, and characteristics. Situatedness provides an explicit demonstration of the individualistic character of knowledge, cognition, and learning. A key point in the brief review is that situatedness becomes a fundamental part of the knowledge we hold. The complex concept of teacher knowledge is further reviewed through Shulman and Shulman's (2004) four categories of teacher knowledge. These categories demonstrate that teacher knowledge is multifaceted and beyond intellectual abilities, pedagogies, and academic content. In fact, it is necessary to recognize that 'understanding and ability' is only 
one portion of the whole. Furthermore, much of the current literature on teacher knowledge is positioned within various theoretical perspectives in education, including: cognitive constructivist, behaviourist, sociocultural, etc. While these perspectives are valued in the discussion, this paper uses the conceptual framework of wholism to incorporate all perspectives found, regarding the layers of development. From this approach, teacher knowledge is both the conscious and unconscious aspects that impact or influence teaching. Through this lens, the person is equally as important as their competencies.

It is only recently that research has focused on the hidden side of teaching, in hopes of grasping a greater understanding of the determinants and influences underlying behaviour. While many researchers attempt to formulate an effective teacher education model based on teacher knowledge research, this paper attempted only to explore its truly multivariate essence, as well as the importance of a harmonious balance between all variables. However, based on the findings of resistance from teachers, with regard to inner exploration, the wholistic approach of mindfulness was highlighted. Mindfulness may provide teachers with the open willingness to become stronger thinkers, questioners, and ultimately, knowers. Mindfulness may be a significant component necessary in teacher development, in order for teachers to truly experience the intrinsic devotion to professional growth and improvement, as well as the skills and abilities necessary in the field. The interconnectedness of mindful learning embraces the dynamic, individual, and personal learning needs of teachers. Rather than being a solution or answer to Shulman's questions, mindfulness may simply be one more of the key components of teacher knowledge.

It is necessary to consider the implications of a wholistic framework in teacher education curriculum, pedagogy, and credentialing. A program geared towards mindful practice may positively influence the impact teachers have on the profession. It is also recommended that there be further exploration of the overlaps and challenges of wholism, mindfulness, and teacher knowledge, to better grasp the overall concept. While Shulman's (1986) questions remain unanswered, the incorporation of sociocultural theoretical frameworks, narrative inquiry approaches, impediments, and integrations of whole-person development, may continue to illuminate aspects of their respective answers. 
Nina Lee Webster is pursuing a PhD in Educational Studies, specialization in Cognition and Learning, at Brock University. She is also a Learning Strategist at Ridley College and her research areas include teacher preparedness, equitable and inclusive education, teacher research, and Learners of English as an Additional Language (LEAL).

\section{References}

Ahmadian, M. A., \& Tavakoli, M. (2011). Exploring the utility of action research to investigate second-language classrooms as complex systems. Educational Action Research, 19(2), 121-136. doi: 10.1080/09650792.2011.569160

Beattie, M., Dobson, D., Thornton, G., \& Hegge, L. (2007). Interacting narratives: Creating and re-creating the self. International Journal of Lifelong Education, 26(2), 119-141. doi: 10.1080/02601370701219434

Briggs, J., \& Peat, F. (1989). Turbulent mirror: An illustrated guide to chaos theory and the science of wholeness. New York, NY: Harper \& Row.

Brown, J. S., Colins, A., \& Duguid, P. (1989). Situated cognition and the culture of learning. Educational Researcher, 18(1), 32-42. doi: 10.3102/0013189X018001032

Chai, C. S., Koh, J. H. L., \& Tsai, C. (2010). Facilitating preservice teachers' development of technological, pedagogical, and content knowledge (TPACK). Journal of Educational Technology \& Society, 13(4), 63-73.

Combs, A. W., Blume, R. A., Newman, A. J., \& Wass, H. L. (1974). The professional education of teachers: A humanistic approach to teacher preparation. Boston, MA: Allyn \& Bacon.

Cvetek, S. (2008). Applying chaos theory to lesson planning and delivery. European Journal of Teacher Education, 31(3), 247-256. doi: 10.1080/02619760802208320

De Vries, E. (2003). Educational technology and multimedia from a cognitive perspective: Knowledge from inside the computer, onto the screen, and into our heads? In H. van Oostendorp (Ed.), Cognition in a digital world (pp. 155-174). Mahwah, NJ: Lawrence Erlbaum Associates.

Eilam, B., \& Poyas, Y. (2009). Learning to teach: Enhancing pre-service teachers' awareness of the complexity of teaching-learning process. Teachers and Teaching: Theory and Practice, 15(1), 87-107. doi: 10.1080/13540600802661337

Evans, C., Arnot-Hopffer, E., \& Jurich, D. (2005). Making ends meet: Bringing bilingual education and mainstream students together in pre-service teacher education. Equity \& Excellence in Education, 38, 75-88. doi: 10.1080/10665680590907855

Farrell, T. S. C. (2006). 'The teacher is an octopus': Uncovering pre-service English language teachers' prior beliefs through metaphor analysis. SAGE Publications, 37(2), 236-248.

Flavell, J. H. (2004). Theory-of-mind development: Retrospect and prospect. Merrill-Palmer Quarterly, 50(3), 274-290. doi: 10.1353/mpq.2004.0018

Freeman, D. (2002). The hidden side of the work: Teacher knowledge and learning to teach: A perspective from North American educational research on teacher education in English language teaching. Language Teaching, 35(1), 1-13. doi: 10.1017/S0261444801001720

Gaudelli, W., \& Ousley, D. (2009). From clothing to skin: Identity work of student teachers in culminating field experiences. Teaching and Teacher Education, 25, 931-939.

Hamachek, D. (1990). Effective teachers: What they do, how they do it, and the importance of self-knowledge. In R. P. Lipka \& T. M. Brinthaupt (Eds.), The role of self in teacher development (pp. 189-224). Albany, NY: State University of New York Press.. 
Hole. (n.d.). In Merriam-Webster dictionary online. Retrieved from http://www.merriamwebster.com/dictionary/hole

Hyland, T. (2009). Mindfulness and the therapeutic function of education. Journal of Philosophy of Education, 43(1), 119-131. doi: 10.1111/j.1467-9752.2008.00668.x

Kabat-Zinn, J. (1990). Full catastrophe living: Using the wisdom of your body and mind to face stress, pain and illness. New York, NY: Delta.

Kiraz, E., \& Ozdemir, D. (2006). The relationship between educational ideologies and technology acceptance in preservice teachers. Educational Technology \& Society, 9(2), 152-165. doi: 10.1080/13598660801971641

Korthagen, F. A. J. (2004). In search of the essence of a good teacher: Towards a more wholistic approach in teacher education. Teaching and Teacher Education, 20(1), 77-97. doi: 10.1016/j.tate.2003.10.002

Langer, E. J. (2000). Mindful learning. Current Directions in Psychological Science (WileyBlackwell), 9(6), 220-223. doi: 10.1111/1467-8721.00099

Maha Thera, N. (1990). A manual of Abhidhamma: Abhidhammattha Sangaha. Somerville, MA: Wisdom Publications.

Martinez, M. E. (2010). Learning and cognition: The design of the mind. Upper Saddle River, NJ: Pearson Education.

Musanti, S. I., \& Pence, L. (2010). Collaboration and teacher development: Unpacking resistance, constructing knowledge, and navigating identities. Teacher Education Quarterly, 37(1), 73-89.

Putnam, R. T., \& Borko, H. (2000). What do new views of knowledge and thinking have to say about research on teacher learning? Educational Researcher, 29(1), 4-15. doi: 10.3102/0013189X029001004

Shulman, L. (1986). Those who understand: Knowledge growth in teaching. Educational Researcher, 15(2), 4-14. doi: 10.3102/0013189X015002004

Shulman, L. S. (1987). Knowledge and teaching: Foundations of the new reform. Harvard Educational Review, 57(1), 1-22.

Shulman, L. S., \& Shulman, J. H. (2004). How and what teachers learn: A shifting perspective. Journal of Curriculum Studies, 36(2), 257-271. doi: 10.1080/0022027032000148298

Tremmel, R. (1993). Zen and the art of reflective practice in teacher education. Harvard Educational Review, 63(4), 434-458.

Tuinamuana, K. (2007). Reconstructing dominant paradigms of teacher education: Possibilities for pedagogical transformation in Fiji. Asia-Pacific Journal of Teacher Education, 35(2), 111-127. doi: 10.1080/13598660701268544

Valentine, L., \& Ivey, M. (2008). Sustaining ambiguity and fostering openness in the (design) learning environment. Art, Design \& Communication in Higher Education, 7(3), 155167. doi: 10.1386/adch.7.3.155_1

Verloop, N., Driel, J. V., \& Maijer, P. (2001). Teacher knowledge and the knowledge base of teaching. International Journal of Educational Research, 35(5), 441-461.

doi: 10.1016/S0883-0355(02)00003-4

Whole. (n.d.). In Merriam-Webster dictionary online. Retrieved from http://www.merriamwebster.com/dictionary/whole

Wubbels, T. (1992). Taking account of student teachers' preconceptions. Teaching and Teacher Education, 8(2), 137-149. doi: 10.1016/0742-051X(92)90004-M 